Research Article

\title{
Hematological and Biochemical Profile of Patients Infected with Schistosoma mansoni in Comparison with Apparently Healthy Individuals at Sanja Town, Northwest Ethiopia: A Cross- Sectional Study
}

\author{
Nega Dessie, Wossenseged Lema $(\mathbb{D}$, and Mulugeta Aemero $\mathbb{D}$ \\ Department of Medical Parasitology, CMHS, University of Gondar, Gondar, Ethiopia \\ Correspondence should be addressed to Mulugeta Aemero; bmeskel@gmail.com
}

Received 7 March 2020; Revised 14 April 2020; Accepted 25 April 2020; Published 6 May 2020

Academic Editor: Aditya Prasad Dash

Copyright ( $\odot 2020$ Nega Dessie et al. This is an open access article distributed under the Creative Commons Attribution License, which permits unrestricted use, distribution, and reproduction in any medium, provided the original work is properly cited.

\begin{abstract}
Background. Schistosomiasis is a parasitic disease that resides in the vascular system of vertebrates, causing a chronic, debilitating disease that affects more than 200 million people and 800,000 deaths per year in over 70 countries. This parasite causes liver dysfunction and disorders normal hematological and biochemical profiles in addition to portal vein hypertension syndrome, ascites, and liver fibrosis. The general objective of the current study is to assess hematological and biochemical profiles of patients infected with Schistosoma mansoni in comparison with apparently healthy individuals (control group) in Sanja town, northwest Ethiopia. Method. A comparative cross-sectional study was conducted from February to April 2019 among microscopically confirmed S. mansoni-infected patients attending Sanja hospital and apparently healthy (control group) from Sanja town community. A total of 220 participants, 110 from the S. mansoni-infected and 110 from the control group, were enrolled using convenient sampling technique. Three grams of stool and six milliliters of blood samples were collected from each study participant. Stool samples were processed using the Kato-Katz technique to determine infection and count parasite density. The blood sample was processed for the analysis of hematological and biochemical profiles using Cell Dyn 1800 (Abbot Hematology, IL, USA) and iChem 535 chemistry analyzer, respectively. All data were analyzed using SPSS version 20, and $P$ value less than 0.05 was taken as statistically significant. Results. This study showed that the mean values of serum alanine aminotransferase, aspartate aminotransferase, total protein, total cholesterol, hemoglobin, mean corpuscular hemoglobin concentration, and total white blood cell count were different in the Schistosoma mansoni-positive group as compared with the control group with statistically significant value $(P \leq 0.05)$. However, the mean values of blood glucose, red blood cell, packed cell volume, and granulocyte count difference were not statistically significant $(P \geq 0.05)$. The mean value of hemoglobin, red blood cells, blood glucose, mean corpuscular hemoglobin concentration, total protein, total cholesterol, and total white blood cell was significantly dropped in the moderate and heavy S. mansoni parasitic load patients as compared with the control group and light $S$. mansoni parasite density patients. However, the mean of AST and ALT progressively elevated as the burden of S. mansoni increased. Conclusion. Most hematological and biochemical profiles were significantly lower in the Schistosoma mansoni-positive group as compared with the control group. Most hematological and biochemical profiles decline significantly as the parasite density increased. Hence, with Schistosoma treatment, supportive treatment against hematological and biochemical disorders is recommended.
\end{abstract}

\section{Background}

Schistosomiasis is a chronic parasitic disease caused by a trematode blood fluke of the genus Schistosoma which belongs to the Schistosomatidae family, namely, Schistosoma mansoni, Schistosoma hematobium, Schistosoma intercalatum, Schistosoma mekongi, and Schistosoma japonicum [1]. Schistosomiasis is the second most widespread human parasitic disease next to malaria [2]. This parasite mostly affects developing countries. It affects more than 200 million people [1] and causes 800,000 deaths per year in over 70 countries [3]. Clinical presentation and pathology of 
schistosomiasis are associated with the species causing the disease, where it resides, and the intensity of infection [3].

Schistosoma pathogenesis is mainly associated with the host's responses to Schistosoma egg antigens to form granulomas usually in the intestines and the liver where the eggs are trapped [4]. Schistosome eggs that do not successfully pass through the intestinal mucosa towards the lumen are usually carried by the portal vein blood flow to the liver inside small presinusoidal and blocking the vessels elicit strong granuloma [5].

Chronic egg-induced granulomas can lead to chronic hepatitis, portal hypertension, bleeding esophageal varices, liver failure, and eventually may lead to death [6]. Another health impact of S. mansoni-infected patients is anemia [7]. The intensity of the infection is a crucial factor which can determine clinical manifestations and severity of the disease, but also, other factors, such as superimposed infections, malnutrition, and genetic background, may play a role [8]. Consequently, schistosomiasis causes diarrhea, fatigue, and anemia at the early stage of infection and portal vein hypertension syndrome, ascites, and liver fibrosis at the later stages [1]. Schistosomiasis also affects the host hematological profiles either by direct ingestion through the gut or aggravation of blood loss through feces by rupturing the blood vessels by the help of the egg spine [9]. A wide range of liver damage has been described in human infections. These include impaired protein synthesis, liver fibrosis [10], and reduced total protein concentrations [11]. Previous study had demonstrated that an adult male and female worm ingested about 100 and $900 \mathrm{nl}$ of blood into their gut per day, respectively [12]. A study conducted in Sudan indicated that most hematological profiles like hemoglobin $(\mathrm{Hgb})$, red blood cell (RBC) count, packed cell volume (PCV), mean corpuscular volume (MCV), mean corpuscular hemoglobin $(\mathrm{MCH})$, mean corpuscular hemoglobin concentration (MCHC), differential leukocyte, and total white blood cell (WBC) count were significantly reduced in S. mansoni-infected patients as compared with the control group [13].

Although different epidemiological research studies on Schistosoma mansoni are conducted in the current study area, there is no report on hematological and biochemical profiles of patients infected with $S$. mansoni. Hence, the objective of the current study was to assess hematological and biochemical profiles of patients infected with Schistosoma mansoni in comparison with apparently healthy individuals (control group) in Sanja town, northwest Ethiopia.

\section{Methods}

2.1. Study Area. The study was conducted in Sanja town, located about $792 \mathrm{~km}$ away from Addis Ababa in Amhara region, northwest Ethiopia. The area has an altitude of $1,800 \mathrm{~m}$ above sea level with $\mathrm{N} 12^{\circ} 59^{\prime} \mathrm{E} 37^{\circ} 18^{\prime}$ coordinates, and its annual rainfall and average temperature range from 800 to $1,800 \mathrm{~mm}$ and $25^{\circ} \mathrm{C}$ to $42^{\circ} \mathrm{C}$, respectively [14]. A total of 162,250 populations live in this district. There are 9 health centers and one district hospital under this district. More than 162,250 populations have access for health service delivery by Sanja hospital [15].
2.2. Study Design and Period. A comparative cross-sectional study was conducted from February 2019 to March 2019 among microscopically confirmed S. mansoni patients attending Sanja hospital and apparently healthy individuals (control group) from Sanja town community.

2.3. Study Population. All Schistosoma mansoni-positive subjects whose age is 5 years and above attending Sanja hospital and apparently healthy subjects in the community were considered as the study population.

\subsection{Sample Size Determination and Sampling Technique.} Double population means (sample size for each group) formula was used. A minimum of 110 participants positive for S. mansoni infection and 110 S. mansoni-negative control groups were enrolled.

The formula $N=\left(S_{1}^{2}+S_{2}^{2}\right)(\alpha, \beta) /\left(U_{1}-U_{2}\right)^{2}$, was used to calculate sample size where $\beta=0.1$ (power 90) and $\alpha=5 \%$ (confidence interval 95\%) two side $t$ test $f(\alpha, \beta)=\left(Z_{\alpha / 2}+Z_{\beta}\right)^{2}$ $=(1.96+1.28)^{2}=10.5$ for two sided test $=(0.22)^{2}+(0.23)^{2}$ $(1.96+1.28)^{2} /(2.2-2.3)^{2}=100$ for each group 100 study participants needed, total $=200$, then $10 \%$ nonresponse rate was added $200 * 10 / 100=20$. The total sample size was 220 , and $U_{1}$ and $S_{1}^{2}$ are the mean and the variance of the control group, respectively. $U_{2}$ and $S_{2}^{2}$ are the mean and the variance of the S. mansoni-infected group, respectively [16].

\subsection{Stool Sample Collection and Processing}

\subsubsection{Microscopic Diagnosis of Schistosoma mansoni.} Three grams of the fresh stool sample were collected using clean, dry, and screw-capped plastic containers labeled with unique identification. Stool samples were processed through the direct wet mount for detection of parasites and Kato-Katz technique using a standardized template measuring $41.7 \mathrm{mg}$ of the stool to prepare a thick smear for detection and quantification of the density of S. mansoni ova for infected participants [17].

2.5.2. Blood Sample Collection. Six milliliters of venous blood was collected by experienced blood collectors using a sterile disposable plastic syringe after cleaning the venous puncture site with $70 \%$ ethanol. Three milliliters of blood was transferred into the ethylene diamine tetra acetic acid (EDTA) test tube for hematological profile analysis. The remaining $3 \mathrm{ml}$ was placed in a plane test tube for analysis of biochemical profiles $[18,19]$.

2.6. Determination of Hematological Parameters. The $3 \mathrm{ml}$ blood in the EDTA tube was dispensed and analyzed by Cell Dyn 1800 (Abbot Hematology, IL, USA) for the determination of complete blood cell count [20].

2.7. Serum Biochemical Analysis. Three milliliters of blood in the anticoagulant-free (plane) test tube was allowed to clot at bench top at least for 30 minutes. Then, it was centrifuged at 2,500 revolutions per minute for 4 minutes, and serum was 
TABLE 1: Sociodemographic characteristics and independent $t$ comparisons mean difference between hematological profiles in S. mansonipositive and control study participants at Sanja town, northwest Ethiopia, 2019.

\begin{tabular}{lcc}
\hline Parameter & $\begin{array}{c}\text { S. mansoni positive }(N=110) \\
\text { Mean } \pm \text { SD }\end{array}$ & $\begin{array}{c}\text { Control group }(N=110) \\
\text { Mean } \pm \text { SD }\end{array}$ \\
\hline Mean age and standard division & $30.90 \pm 9.11$ & $31.11 \pm 13.20$ \\
Sex & & $55(50 \%)$ \\
$\quad$ Male & $55(50 \%)$ & $55(50 \%)$ \\
Female & $55(50 \%)$ & $55(50 \%)$ \\
Residence & & $55(50 \%)$ \\
$\quad$ Urban & $55(50 \%)$ & $0 \%$ \\
$\quad$ Rural & $55(50 \%)$ & $0 \%$ \\
Parasite intensity & & $0 \%$ \\
Light & $76(69.1 \%)$ & $7.81 \pm 3.44$ \\
Moderate & $31(28.2)$ & $2.48 \pm 1.32$ \\
Heavy & $3(2.7 \%)$ & $1.55 \pm 1.29$ \\
WBC $\left(\times 10^{3} / \mu \mathrm{L}\right)$ & $4.60 \pm 1.61$ & $4.03 \pm 2.07$ \\
L $\left(\times 10^{3} / \mu \mathrm{L}\right)$ & $1.50 \pm 0.61$ & $4.04 \pm 0.65$ \\
Mixed $\left(\times 10^{3} / \mu \mathrm{L}\right)$ & $0.55 \pm 0.53$ & $12.58 \pm 1.67$ \\
Granulocyte $\left(\times 10^{3} / \mu \mathrm{L}\right)$ & $2.63 \pm 1.27$ & $37.51 \pm 0.5 .11$ \\
RBC $\left(\times 10^{6} / \mu \mathrm{L}\right)$ & $3.92 \pm 0.75$ & $87.91 \pm 5.02$ \\
Hgb $(\mathrm{g} / \mathrm{dl})$ & $11.36 \pm 0.1 .89$ & $30.35 \pm 2.95$ \\
PCV $(\%)$ & $34.14 \pm 5.38$ & $34.80 \pm 1.00$ \\
MCV $\left(\mu \mathrm{m}^{3}\right)$ & $92.78 \pm 7.78$ & $<0.001$ \\
MCH $(\mathrm{g} / \mathrm{dL})$ & $28.90 \pm 3.45$ & $<0.001$ \\
MCHC $(\mathrm{Pg})$ & $30.10 \pm 4.10$ & $<0.001$ \\
\end{tabular}

aliquot by an Eppendorf tube. Then, serum was analyzed by using iChem535 chemistry analyzer for serum level of AST, ALT, blood glucose, total protein, and serum total cholesterol [21].

2.8. Data Analysis. Data were registered into Statistical Package for Social Sciences (SPSS) version 20 for statistical analysis of mean and standard deviations, while the differences between the study and the control groups were assessed using the independent $t$-test and one-way ANOVA. The $P$ value with $95 \%$ of confidence interval was used to determine the association between the dependent and independent variables. Statistical significance was considered at a $95 \%$ level of confidence and $P$ value less than 0.05 .

2.9. Ethical Considerations. The study was conducted after ethical approval was obtained from the Research and Ethics committee of the School of Biomedical and Laboratory Sciences, College of Medicine \& Health Sciences, University of Gondar. Moreover, letter of support was secured from the Sanja district health office and community leader. Before starting the actual data collection, permission was obtained from the hospital director. Additionally, after explaining the purpose, benefits, and the possible risks of the study, informed written consent was obtained from the study participants or their guardians. All laboratory results were kept confidential. Apparently, those positive for parasite and with hematological and biochemical abnormality were linked to the hospital and health center for appropriate treatment. The treatment cost was covered by communicating with the zonal and district health administrators.

\section{Results}

A total of 220 subjects were recruited for this study. Of these, 110 were $S$. mansoni-positive, and the remaining were apparently healthy control group. Age ranged from 8 to 60 years with a mean age of $30.90 \pm 9.11$ for $S$. mansoni positive and $31.11 \pm 13.20$ for the control group. Half (110/220) of the participants were males and rural in residence. The majority (69.1\%) of S. mansoni-positive individuals had a light parasite density (Table 1).

In the current study, the mean total WBC count in the $S$. mansoni-infected subject was low as compared with the apparently healthy control group with a mean and standard deviation of $4.60 \pm 1.61$ and $7.81 \pm 3.44$, respectively. Similarly, the mean RBC count was slightly lower in the S. mansonipositive group as compared with the control group, $3.92 \pm 0.75$ and $4.04 \pm .65$, respectively (Table 2 ). The mean $\mathrm{Hgb}$ concentration of the $S$. mansoni-positive group and the control group was $11.36 \pm .1 .89$ and $12.58 \pm 1.67$, respectively (Table 1).

The mean blood glucose level was lower in the $S$. mansoni-infected group than the control group $(99.71 \pm 18.67 \& 104.13 \pm 16.63)$, respectively, without a statistically significant association $(P>0.05)$. However, the mean serum total protein was significantly lower in the $S$. mansoni-infected group $(68.70 \pm 3.20)$ than the control group $(69.76 \pm 3.03)$. The mean serum AST level was elevated in $S$. mansoni-infected individuals $(24.84 \pm 2.19)$ compared with the control group $(23.86 \pm 2.22)$. The mean ALT level in $S$. mansoni-positive subjects was elevated $(22.67 \pm 4.66)$ compared with the control group $(21.15 \pm 2.27)$ (Table 2).

In the current study, mean of the most hematological profiles significantly $(P<0.05)$ declines with increasing of 
TABLE 2: Independent $t$ comparisons mean the difference between biochemical profiles in $S$. mansoni-positive and $S$. mansoni-negative of study participants, Sanja town, northwest Ethiopia, 2019.

\begin{tabular}{lccc}
\hline \multirow{2}{*}{ Parameter } & S. mansoni positive $(N=110)$ & Control group $(N=110)$ & Mean \pm SD \\
& Mean \pm SD & $104.13 \pm 16.64$ & $P$ value \\
\hline Blood glucose $(\mathrm{mg} / \mathrm{dl})$ & $99.71 \pm 18.67$ & $69.76 \pm 3.0$ & 0.065 \\
Serum protein $(\mathrm{g} / \mathrm{dl})$ & $68.7 \pm 3.20$ & $23.86 \pm 2.22$ & 0.012 \\
AST (IU/L) & $24.84 \pm 2.19$ & $21.15 \pm 2.30$ & 0.01 \\
ALT (IU/L) & $22.70 \pm 4.66$ & $166.47 \pm 18.44$ & 0.02 \\
Cholesterol & $149.08 \pm 9.38$ & $<0.001$ \\
\hline
\end{tabular}

TABLE 3: Association of S. mansoni parasitic intensity with host hematological and biochemical profiles in Sanja town, northwest Ethiopia, 2019 .

\begin{tabular}{|c|c|c|c|c|c|}
\hline Parameter & $\begin{array}{c}\text { Control group (0 epg) } \\
\text { Mean } \pm \text { SD }\end{array}$ & $\begin{array}{l}\text { Light }(1-99 \text { epg }) \\
\text { Mean } \pm \text { SD }\end{array}$ & $\begin{array}{c}\text { Moderate }(100-399 \text { epg }) \\
\text { Mean } \pm \text { SD }\end{array}$ & $\begin{array}{c}\text { Heavy }(\geq 400) \\
\text { Mean } \pm \text { SD }\end{array}$ & $P$ value \\
\hline WBC $\left(\times 10^{3} / \mu \mathrm{L}\right)$ & $7.81 \pm 3.44$ & $4.93 \pm 1.48$ & $4.04 \pm 1.69$ & $2.47 \pm 1.15$ & $<0.001$ \\
\hline $\mathrm{L}\left(\times 10^{3} / \mu \mathrm{L}\right)$ & $2.48 \pm 1.32$ & $1.61 \pm 0.61$ & $1.28 \pm .4971$ & $0.93 \pm 0.92$ & $<0.001$ \\
\hline Mixed $\left(\times 10^{3} / \mu \mathrm{L}\right)$ & $1.55 \pm 1.29$ & $0.58 \pm 0.50$ & $0.51 \pm 0.60$ & $0.43 \pm 0.40$ & $<0.001$ \\
\hline Granulocyte $\left(\times 10^{3} / \mu \mathrm{L}\right)$ & $4.03 \pm 2.07$ & $2.85 \pm 1.17$ & $2.22 \pm 1.39$ & $1.10 \pm 0.17$ & $<0.001$ \\
\hline $\mathrm{RBC}\left(\times 10^{6} / \mu \mathrm{L}\right)$ & $4.04 \pm 0.65$ & $4.21 \pm 1.16$ & $3.53 \pm 0.39$ & $2.52 \pm 0.13$ & $<0.001$ \\
\hline $\mathrm{Hgb}(\mathrm{g} / \mathrm{dl})$ & $12.58 \pm 1.67$ & $12.04 \pm 1.73$ & $10.01 \pm 1.19$ & $8.30 \pm 1.04$ & $<0.001$ \\
\hline PCV (\%) & $37.51 \pm 5.11$ & $35.94 \pm 5.02$ & $30.62 \pm 3.46$ & $24.87 \pm 2.84$ & $<0.001$ \\
\hline $\operatorname{MCV}\left(\mu \mathrm{m}^{3}\right)$ & $86.45 \pm 6.94$ & $92.37 \pm 10.71$ & $93.25 \pm 8.55$ & $98.10 \pm 5.89$ & $<0.001$ \\
\hline $\mathrm{MCH}(\mathrm{g} / \mathrm{dL})$ & $30.35 \pm 2.95$ & $29.65 \pm 3.41$ & $27.31 \pm 2.96$ & $26.20 \pm 3.29$ & $<0.001$ \\
\hline $\mathrm{MCHC}(\mathrm{Pg})$ & $34.80 \pm 1.00$ & $30.79 \pm 4.06$ & $28.68 \pm 3.69$ & $27.30 \pm 5.72$ & $<0.001$ \\
\hline Blood glucose $(\mathrm{mg} / \mathrm{dl})$ & $104.13 \pm 16.63$ & $107.15 \pm 15.90$ & $83.87 \pm 13.16$ & $75.00 \pm 4.33$ & $<0.001$ \\
\hline Serum protein $(\mathrm{g} / \mathrm{dl})$ & $69.76 \pm 3.03$ & $69.63 \pm 2.84$ & $66.69 \pm 3.12$ & $65.97 \pm 1.15$ & $<0.001$ \\
\hline AST (U/L) & $23.86 \pm 2.22$ & $24.28 \pm 2.11$ & $25.96 \pm 1.82$ & $27.43 \pm 1.15$ & $<0.001$ \\
\hline $\operatorname{ALT}(\mathrm{U} / \mathrm{L})$ & $21.15 \pm 2.27$ & $22.30 \pm 5.37$ & $23.45 \pm 2.32$ & $24.93 \pm 64$ & 0.005 \\
\hline Total cholesterol $(\mathrm{mg} / \mathrm{dl})$ & $166.47 \pm 18.43$ & $151.33 \pm 9.06$ & $144.15 \pm 8.46$ & $143.00 \pm 5.00$ & $<0.001$ \\
\hline
\end{tabular}

parasite intensity. The mean value of $\mathrm{HGB}, \mathrm{HCT}, \mathrm{MCH}$, $\mathrm{MCHC}$, blood glucose, total protein, total cholesterol, and total WBC was significantly $(P<0.05)$ dropped in the moderately and heavily $S$. mansoni-infected patients compared with the control group and those with light S. mansoni egg density $(P<0.05)$. However, the mean value of AST was progressively elevated as the intensity of $S$. mansoni infection increased $(P<0.001)$ (Table 3$)$.

\section{Discussion}

Schistosomiasis remains one of the most important but neglected tropical diseases in Ethiopia [22]. In the current study, the intensity of S. mansoni infection was $69.1 \%$ light, $28.2 \%$ moderate, and $2.7 \%$ heavy. This result is nearly similar to the result that is previously reported from Azezo, northwest Ethiopia, 67.8\%, 19.8\%, and, 3.1\% light, moderate, and heavy intensity, respectively [23]. The current study result is quite different from another report from Sanja, northwest Ethiopia, 0\% light, 86.2\% moderate, and 13.8\% heavy intensity of infection [24]. Another study in Gorgora town, northwest Ethiopia, had reported 13.1\% light, 7.1\% moderate, and $0.3 \%$ heavy intensity of infection [25]. There was another incomparable report from southwest Ethiopia, where $57 \%$ light, $26.7 \%$ moderate, and $16.3 \%$ heavy intensity of infection had been reported [26]. The possible difference across the studies might be due to the age of the study participant, mass drug administration programs, immunity of the host, frequency of individual contact with contaminated water bodies, the burden of the adult worms hosted, sample size, and sampling techniques.

In the present study, the $S$. mansoni-positive subjects had significantly $(P<0.001)$ lower mean of total WBC count as compared with the control group. This result is nearly comparable to the results of previously reported findings from a study in Nigeria, $2.5 \times 10^{3} \pm 0.12$ and $8.0 \times 10^{3} \pm 2.10$, $S$. mansoni-positive and the control group, respectively [16]. In the current study, increased intensity of infection also significantly $(P<0.05)$ dwindled the mean total WBC in severely and moderately infected subjects as compared with the mildly infected group. The current study result was quite lower from a report from Sudan whose mean value of WBC in mild $\left(7.5319 \times 10^{3}\right)$ and severe $\left(6.884 \times 10^{3}\right)$ infected patients was high [27]. Schistosoma mansoni like other helminth parasites manipulates the host immune response toward their comfortable condition. Therefore, observed changes in circulating total WBC numbers following $S$. mansoni infection are linked to the basic immune response to the parasite and also to induced biased proliferation or decrease in specific immune cells according to the disease stage and density [28]. The current study showed significant $(P<0.05)$ degree elevation of the granulocyte (neutrophil and eosinophil) in the $S$. mansoni-infected subject as compared with the control group. During the acute infections with tissue-migrating larvae or following the sudden release of antigens from parasites dying either spontaneously 
or following chemotherapy is characterized by Schistosomainduced eosinophil elevation [29].

In the present study, there was no significant $(P>0.05)$ decrease in the mean erythrocytic parameters (the mean values of RBC count and PCV) below the normal range in the $S$. mansoni-infected subject as compared with the control group. The risk is also negatively associated with the burden of the parasite density. This result was slightly lower from a previous study in China with means of RBC $4.64 \times 10^{6} / \mathrm{UL}$ (Schistosoma-positive) and $4.7 \times 10^{6} / \mathrm{UL}$ (control group) [30]. The decrease in RBC count might be due to the reduction in erythropoiesis in the bone marrow, massive blood consumption by female and male S. mansoni worms [9], and enhanced hemolysis of peripheral RBC in the spleen or chronic blood loss through stool [31, 32].

The result from this study showed significantly $(P<0.001)$ dropped mean $\mathrm{Hgb}$ concentration with a cutoff point $(<12)$ suggesting for anemia in $S$. mansoni-positive individuals as compared with the control group. This finding is in agreement with a result reported from west Burkina Faso which showed a mean value of HGB $(\mathrm{g} / \mathrm{dL}) 11.57 \pm 0.7$ 6 in Schistosoma-positive and $11.86 \pm 1.51$ in the control group [33]. In the current study, the mean Hgb concentration was also significantly $(P<0.001)$ dropped as the intensity of infection increased. Subjects with heavy infection density were more anemic than those with light and moderate infection. This finding is supported by other findings from western Kenya with a mean $\mathrm{Hgb}(\mathrm{g} / \mathrm{dL}) 11.6$ in the control group and with light (11.9), moderate (11.3), and (10.9) heavy Schistosoma mansoni infection [34]. Another study from Sudan reported mean $\mathrm{Hgb}(\mathrm{g} / \mathrm{dL})$ value among mild (13.406) and severe (11.692) infections [27].

The decrease in $\mathrm{Hgb}$ can be related to the reduction in size of RBC, impaired biosynthesis of heam in the bone marrow, due to reduction in the rate of formation of RBC [35] or can be attributed to chronic blood loss that results from the bleeding induced by migration of worms through the intestinal wall or due to blood consumption by adult schistosomes. In addition, this could be from direct competition with the human host for iron in the intestinal and blood stages of the parasite [36].

In the present study basic results, the mean $\mathrm{MCH}$ and MCHC were significantly $(P<0.05)$ lower in the $S$. mansonipositive group as compared with the control group. This finding was comparable with another recent report from Ghanaian study that showed mean of MCH $23.72 \pm 0.43$ in the $S$. mansoni-positive group and $26.21 \pm 0.31$ in the control group and mean of MCHC $31.25 \pm 0.27$ in the S. mansonipositive group and $32.21 \pm 0.19$ in the control group [37]. A study in Burkina Faso showed a mean MCH of $26.26 \pm 1.83$ value in the $S$. mansoni-positive group and $27.12 \pm 2.82$ in the control group, while the MCHC value was $33.02 \pm 0.61$ and $32.98 \pm 0.72$ in the $S$. mansoni-positive and control group, respectively [33].

The results from this present study showed that the mean blood glucose level was not significantly $(P>0.05)$ decreased in the $S$. mansoni-positive group as compared with the control group. Previous study in China reported a mean blood glucose level of $5.33 \mathrm{mmol} / \mathrm{L}(96 \mathrm{mg} / \mathrm{dl})$ and
$5.56 \mathrm{mmol} / \mathrm{L}(100.1 \mathrm{mg} / \mathrm{dl})$ in the Schistosoma-positive group and the control group, respectively [30]. However, those with high intensity of infection have significantly lower glucose level compared with the control study subjects. Structural damage of the host gastrointestinal mucosa can lead to loss and malabsorption of nutrients, reducing food intake, increasing nutrient excretion, vomiting, diarrhea, or altering nutrient metabolism within the body or direct consumption of huge host blood glucose [12].

The current result shows mean of total protein was significantly $(P<0.05)$ declined in the $S$. mansoni-positive group as compared with the control group. This finding agrees with a study from Sudan where a mean total protein of $68 \pm 0.1$ and $76 \pm 0.1$ in the S. mansoni-positive and control group, respectively, was reported [13]. This result is also supported by another study from Nigeria with a mean value of $50.2 \pm 2.10$ and $71.0 \pm 3.22$ in the $S$. mansoni-infected and control group, respectively [16]. The possible reason for reduction of serum protein could be due to impaired protein synthesis [38], a massive amount of plasma protein consumption for the parasite metabolism, development, and growth [39].

The present study showed an elevated mean value of ALT and AST in the S. mansoni-positive group as compared with the control group. The previous study from Nigeria reported a mean AST and ALT value in the $S$. mansoni-positive group $(25.0 \pm 0.63$ and $20.1 \pm 0.68)$ and in the control group $(6.2 \pm 0.18$ and $7.1 \pm 0.2)$, respectively [16]. The possible causes might be due to damages on the membrane of the liver, hepatic manifestations originating from the deposition of eggs inside the small vessels of the liver which can lead to an intense inflammatory response and subsequent functional changes, a situation which presumably may be responsible for significant elevation of these circulating liver enzymes $[11,40]$.

The mean total cholesterol level was significantly $(P<0.05)$ dropped in the $S$. mansoni-infected subject as compared with the control group in the current study. This finding is supported by a study from Brazil, which reported a mean total cholesterol level of $123.90 \pm 21.52$ and $156.31 \pm 41.50$ for the S. mansoni-positive group and the control group, respectively [41]. The possible cause for reduction of blood total cholesterol in infected hosts might be due to abnormalities in lipid metabolism, and since Schistosoma did not synthesize cholesterol de novo, it is completely dependent on the host cholesterol and fatty acids [42].

\section{Conclusion}

In the present study, the mean concentrations of ALT, AST, $\mathrm{Hgb}, \mathrm{MCH}, \mathrm{MCHC}$, total protein, total cholesterol, and WBC count were significantly altered in the S. mansoniinfected patients as compared with the control group.

Severely parasitized patients showed a significant reduction in their mean $\mathrm{MCH}, \mathrm{MCHC}$, Hgb, blood glucose, total protein, and total cholesterol when compared with mildly and moderately infected study subjects. In general, the study showed that the hematological and biochemical 
profiles of patients infected with Schistosoma mansoni were impaired compared with the normal level and control group. Therefore, schistosomiasis control programs should be strengthened in the study area and elsewhere to decrease its transmission. Other than treatment with Praziquantel, supportive treatment to alleviate health impairment due to hematological and biochemical disorders induced by $S$. mansoni infection should be considered.

\section{Data Availability}

All data are available within the article.

\section{Conflicts of Interest}

The authors declare that they have no conflicts of interest.

\section{References}

[1] B. Gryseels, K. Polman, J. Clerinx, and L. Kestens, "Human schistosomiasis," The Lancet, vol. 368, no. 9541, pp. 1106-1118, 2006.

[2] L. Chitsulo, D. Engels, A. Montresor, and L. Savioli, "The global status of schistosomiasis and its control," Acta Tropica, vol. 77, no. 1, pp. 41-51, 2000.

[3] B. Bruun and J. Aagaard-Hansen, The Social Context of Schistosomiasis and its Control: An Introduction and Annotated Bibliography, World Health Organization, Geneva, Switzerland, 2008.

[4] E. Bindseil, T. Iburg, M. H. Hurst, and M. V. Johansen, "Distinguishing periportal fibrosis from portal fibrosis in hepatic schistosomiasis," Trends in Parasitology, vol. 20, no. 8, pp. 361-362, 2004.

[5] Z. A. Andrade, "Schistosomiasis and liver fibrosis," Parasite Immunology, vol. 31, no. 11, pp. 656-663, 2009.

[6] M. Hesse, C. A. Piccirillo, Y. Belkaid et al., "The pathogenesis of schistosomiasis is controlled by cooperating IL-10-producing innate effector and regulatory T cells," The Journal of Immunology, vol. 172, no. 5, pp. 3157-3166, 2004.

[7] N. Midzi, D. Sangweme, S. Zinyowera et al., "Efficacy and side effects of praziquantel treatment against Schistosoma haematobium infection among primary school children in Zimbabwe," Transactions of the Royal Society of Tropical Medicine and Hygiene, vol. 102, no. 8, pp. 759-766, 2008.

[8] World Health Organization, Progress in Assessment of $M$ Orbidity Due to Schistosoma Manson! Infection: A Review of Recent Literature, World Health Organization, Geneva, Switzerland, 1997.

[9] J. D. Lawrence, "The ingestion of red blood cells by Schistosoma mansoni," The Journal of Parasitology, vol. 59, no. 1, pp. 60-63, 1973.

[10] A. Montresor, T. W. Gyorkos, D. W. Crompton, D. Bundy, L. Savioli, and W. H. Organization, Monitoring Helminth Control Programmes: Guidelines for Monitoring the Impact of Control Programmes Aimed at Reducing Morbidity Caused by Soil-Transmitted Helminths and Schistosomes, with Particular Reference to School-Age Children, World Health Organization, Geneva, Switzerland, 1999.

[11] F. L. d. Silva, R. P. Del-Rei, D. B. M. Fraga, L. M. Leony, A. M. G. C. d. Souza, and F. L. N. Santos, "Alterations in the lipid profiles and circulating liver enzymes in individuals infected by Schistosoma mansoni," Revista da Sociedade
Brasileira de Medicina Tropical, vol. 51, no. 6, pp. 795-801, 2018.

[12] P. J. Skelly, A. A. Da'dara, X.-H. Li, W. Castro-Borges, and R. A. Wilson, "Schistosome feeding and regurgitation," PLoS Pathogens, vol. 10, no. 8, Article ID e1004246, 2014.

[13] E. H. Mohammed, M. Eltayeb, and H. Ibrahim, "Haematological and biochemical morbidity of Schistosoma haematobium in school children in Sudan," Sultan Qaboos University Medical Journal, vol. 6, no. 6, pp. 59-64, 2006.

[14] A. Koukounari, B. B. A. Estambale, J. Kiambo Njagi et al., "Relationships between anaemia and parasitic infections in Kenyan schoolchildren: a Bayesian hierarchical modelling approach," International Journal for Parasitology, vol. 38, no. 14, pp. 1663-1671, 2008.

[15] Sanja District Health Office, Central Gondar Zone, Amhara Regional State, Ethiopia, Annuall Report for the Fisical Year, 2018.

[16] E. T. Egoro, G. I. Ilegbedion, Z. Udu Loveday, and M. S. Shonibare, "Blood biochemical and haematological alterations in Schistosoma mansoni infected patients in Ijora-Badia Nigeria," European Journal of Biomedical and Pharmaceutical Sciences, vol. 4, no. 11, pp. 148-152, 2017.

[17] World Health Organization, Prevention and Control of Schistosomiasis and Soil-Transmitted Helminthiasis, Vol. 912, World Health Organization Technical Report Series, Geneva, Switzerland, 2002.

[18] J. V. Dacie and S. M. Lewis, Practical Haematology, Churchill Livingstone, London, UK, 1975.

[19] A. Yalew, B. Terefe, M. Alem, and B. Enawgaw, "Hematological reference intervals determination in adults at Gondar university hospital, Northwest Ethiopia," BMC Research Notes, vol. 9, no. 1, p. 483, 2016.

[20] MHR, Medical Laboratory Hematology, Butterworth-Heinenmann Ltd., Oxford, UK, 2nd edition, 1991.

[21] S. Reitman and S. Frankel, "A colorimetric method for the determination of serum glutamic oxalacetic and glutamic pyruvic transaminases," American Journal of Clinical $\mathrm{Pa}$ thology, vol. 28, no. 1, pp. 56-63, 1957.

[22] K. Deribe, K. Meribo, T. Gebre et al., "The burden of neglected tropical diseases in Ethiopia, and opportunities for integrated control and elimination," Parasites \& Vectors, vol. 5, no. 1, p. 240, 2012.

[23] A. Gelaw, B. Anagaw, B. Nigussie et al., "Prevalence of intestinal parasitic infections and risk factors among schoolchildren at the University of Gondar Community School, Northwest Ethiopia: a cross-sectional study," BMC Public Health, vol. 13, no. 1, p. 304, 2013.

[24] E. Woldegerima, A. G. Bayih, Y. Tegegne, M. Aemero, and A. Jejaw Zeleke, "Prevalence and reinfection rates of Schistosoma mansoni and praziquantel efficacy against the parasite among primary school children in Sanja town, northwest Ethiopia," Journal of Parasitology Research, vol. 2019, Article ID 3697216, 8 pages, 2019.

[25] T. Essa, Y. Birhane, M. Endris, A. Moges, and F. Moges, "Current status of Schistosoma mansoni infections and associated risk factors among students in Gorgora town, Northwest Ethiopia," ISRN Infectious Diseases, vol. 2013, Article ID 636103, 7 pages, 2012.

[26] M. Weltaji, D. Dana, and B. Levecke, "Prevalence and intensity of schistosoma mansoni infections among schoolchildren attending primary schools in an urban setting in Southwest, Ethiopia," BMC Research Notes, vol. 10, no. 1, 2017.

[27] T. E. ElmissbahElmahdi and A. M. A. Malik Hassan Ibrahim Mustafa, "Measuring the impact of schistosomiasis infection 
on different blood parameters," Parasitology, vol. 7, no. 3, 2013.

[28] F. L. Oliveira, P. Frazão, R. Chammas et al., "Kinetics of mobilization and differentiation of lymphohematopoietic cells during experimental murine schistosomiasis in galectin3-/-mice," Journal of Leukocyte Biology, vol. 82, no. 2, pp. 300-310, 2007.

[29] E. M. O'onnell and T. B. Nutman, "Eosinophilia in infectious diseases," Immunology and Allergy Clinics of North America, vol. 35, no. 35, pp. 493-522, 2015.

[30] Q. Duan, L. Xiong, C. Liao et al., "Population based and animal study on the effects of Schistosoma japonicum infection in the regulation of host glucose homeostasis," Acta Tropica, vol. 180, pp. 33-41, 2018.

[31] J. F. Friedman, H. K. Kanzaria, and S. T. McGarvey, "Human schistosomiasis and anemia: the relationship and potential mechanisms," Trends in Parasitology, vol. 21, no. 8, pp. 386-392, 2005.

[32] H. K. Kanzaria, D. L. Manalo, J. D. Kurtis et al., "Schistosoma japonicum and occult blood loss in endemic villages in Leyte, the Philippines," The American Journal of Tropical Medicine and Hygiene, vol. 72, no. 2, pp. 115-118, 2005.

[33] H. Sorgho, O. Da, T. Rouamba, B. Savadogo, H. Tinto, and J.-B. Ouédraogo, "Schistosoma mansoni infection and hematological profile in an endemic foci in Western Burkina Faso," Journal of Parasitology Research, vol. 4, no. 10, 2017.

[34] S. E. Butler, P. M. N. Mwinzi, K. Odhiambo et al., "Mechanism of anemia in schistosoma mansoni-infected school children in western Kenya," The American Journal of Tropical Medicine and Hygiene, vol. 87, no. 5, pp. 862-867, 2012.

[35] R. F. Sturrock, H. C. Kariuki, F. W. Thiongo et al., "Schistosomiasis mansoni in Kenya: relationship between infection and anaemia in schoolchildren at the community level," Transactions of the Royal Society of Tropical Medicine and Hygiene, vol. 90, no. 1, pp. 48-54, 1996.

[36] M. J. Lamyman, D. J. Noble, S. Narang, and N. Dehalvi, "Small bowel obstruction secondary to intestinal schistosomiasis," Transactions of the Royal Society of Tropical Medicine and Hygiene, vol. 100, no. 9, pp. 885-887, 2006.

[37] J. Afrifa, D. Gyedu, E. Ofori Gyamerah, S. Essien-Baidoo, and I. Mensah-Essilfie, "Haematological profile and intensity of urogenital schistosomiasis in ghanaian children," Journal of Environmental and Public Health, vol. 2017, Article ID 4248325, 5 pages, 2017.

[38] L. Camacho-Lobato and D. R. Borges, "Early liver dysfunction in schistosomiasis," Journal of Hepatology, vol. 29, no. 2, pp. 233-240, 1998.

[39] A. M. C. Horemans, A. G. M. Tielens, and S. G. van den Bergh, "The reversible effect of glucose on the energy metabolism of Schistosoma mansoni cercariae and schistosomula," Molecular and Biochemical Parasitology, vol. 51, no. 1, pp. 73-79, 1992.

[40] S. Zakaria, G. Esmat, K. Serag, and T. Elbaz, "Schistosomiasis and its impact on the liver and gut," Folia Gastroenterologica et Hepatologica, vol. 5, no. 1, 2007.

[41] E. A. G. Reis, R. E. Blanton, M. L. Barreto et al., "Biochemical and immunologic predictors of efficacy of treatment or reinfection risk for Schistosoma mansoni," The American Journal of Tropical Medicine and Hygiene, vol. 75, no. 5, pp. 904-909, 2006.

[42] F. Meyer, H. Meyer, and E. Bueding, "Lipid metabolism in the parasitic and free-living flatworms, Schistosoma mansoni and Dugesia dorotocephala," Biochimica et Biophysica Acta (BBA)Lipids and Lipid Metabolism, vol. 210, no. 2, pp. 257-266, 1970. 